\title{
In Vitro Dermo-Cosmetic Evaluation of Bark Extracts from Common Temperate Trees
}

Authors

Affiliations
Jane Hubert ${ }^{1}$, Apostolis Angelis ${ }^{1,2}$, Nektarios Aligiannis $^{2}$, Michalea Rosalia ${ }^{2}$, Amin Abedini $^{1,3}$, Ali Bakiri ${ }^{1,4}$, Romain Reynaud $^{4}$, Jean-Marc Nuzillard ${ }^{1}$, Sophie C. Gangloff ${ }^{3}$, Alexios-Leandros Skaltsounis ${ }^{2}$, Jean-Hugues Renault ${ }^{1}$

The affiliations are listed at the end of the article
Key words

- barks

- natural products

- dermo-cosmetics

- DPPH

- Collagenase

- elastas

- tyrosinase

- Staphylococcus aureus

- nuclear magnetic resonance spectroscopy received February 29, 2016

revised May 23, 2016

accepted June 1, 2016

\section{Bibliography}

Dol http://dx.doi.org/

10.1055/s-0042-110180

Published online June 28, 2016

Planta Med 2016; 82:

1351-1358 @ Georg Thieme

Verlag KG Stuttgart · New York

ISSN 0032-0943

\section{Correspondence}

\section{Jane Hubert}

Institut de Chimie Moléculaire de Reims

UMR CNRS 7312

SFR CAP'SANTE

UFR de Pharmacie

Université de Reims

Champagne-Ardenne,

UFR Sciences Exactes et

Naturelles

Moulin de la Housse, BP 1029

51687 Reims Cedex

France

jane.hubert@univ-reims.fr

\section{Abstract}

$\nabla$

Wood residues produced from forestry activities represent an interesting source of biologically active, high value-added secondary metabolites. In this study, 30 extracts from 10 barks of deciduous and coniferous tree species were investigated for their potential dermo-cosmetic use. The extracts were obtained from Fagus sylvatica, Quercus robur, Alnus glutinosa, Prunus avium, Acer pseudoplatanus, Fraxinus excelsior, Populus robusta, Larix decidua, Picea abies, and Populus tremula after three successive solid/liquid extractions of the barks with $n$-heptane, methanol, and methanol/

\section{Introduction}

\section{$\nabla$}

According to the Earth Policy Institute [1] and Food and Agriculture Organization report published in 2011 [2], European countries contain the largest forest area ahead of all other continents, with one billion hectares corresponding to $25 \%$ of the world's forests. Despite the alarming deforestation rate worldwide, between 1990 and 2010, Europe remained the only region with a net increase in forest area. Waste management in the context of forestry activities thus represents an opportunity for the European economy. Barks from conifers and broadleaved trees represent abundant residues generated by forestry activities. Currently, these barks are mainly recycled as fuel or insulation materials, or in horticulture for weed suppression and moisture retention. However, an increasing number of studies have brought to the forefront the diversity of biologically active compounds that can be extracted from barks and upgraded as input materials in high value-added industrial sectors [3-5]. Barks constitute the outermost part of trees, directly wrapping the cambium, which is the thin layer containing channels in which sap flows. From a water. All extracts were evaluated for their radical scavenging capacity, for their elastase, collagenase, and tyrosinase inhibitory activities, as well as for their antibacterial activity against grampositive Staphylococcus aureus. In parallel, the global metabolite profiles of all extracts were established by 1D and 2D NMR and related to their biological activity. The results showed that the methanol extracts of $Q$. robur, A. glutinosa, L. decidua, and $P$. abies barks exhibit particularly high activities on most bioassays, suggesting their promising use as active ingredients in the dermocosmetic industry.

chemical point of view, barks contain a range of secondary metabolites that are biosynthesized to protect the cambium and the inner part of the trunk, which are vital for tree growth and life. These compounds thus represent an interesting source of leads for the production of biologically active pharmaceuticals or cosmetic ingredients. For instance, the alkaloid quinine, firstly isolated from the bark of the Cinchona tree (Rubiaceae) in South America, has played a key role for decades in malaria control worldwide [6]. Still, in the Southern Hemisphere, a range of metabolites isolated from barks of Central African trees has demonstrated interesting antiparasitic properties [7]. In northern regions, placlitaxel, the prototype of the taxane class of chemotherapeutics, was isolated from the bark of Taxus species (Taxaceae) [8]. The pentacyclic triterpene betulin, abundantly found in the outer bark of the birch tree, has been recognized to display a broad spectrum of pharmacological properties, and, particularly, a potential for cancer treatment [9]. Barks from the Walloon Region Forest in Europe have also been reported as promising candidates for the development of anticancer agents [10]. One can also refer to a recent Canadian study that emphasized the 
cosmeceutical potential of polyphenol extracts of a range of barks [11].

The cosmetics industry is a high value and very dynamic industrial sector in which the development of active ingredients of natural origin is exponentially growing. The development of cosmetic ingredients from tree barks can thus be a very interesting option to increase the competitiveness of forestry residues.

In the present study, we investigated a collection of ten barks from common deciduous and coniferous trees growing in temperate forests, including the common beech Fagus sylvatica L. (Fagaceae), the pedunculate oak Quercus robur L. (Fagaceae), the black alder Alnus glutinosa (L.) Gaertn. (Betulaceae), the wild cherry Prunus avium L. (Rosaceae), the sycamore maple Acer pseudoplatanus L. (Sapindaceae), the ash Fraxinus excelsior L. (Oleaceae), the poplar Populus robusta C.K. Schneid. (Saliaceae), the European larch Larix decidua Mill. (Pinaceae), the Norway spruce Picea abies (L.) H.Karst. (Pinaceae), and the American aspen Populus tremula L. (Salicaceae). The objective was to investigate the potential ability of these barks to interfere with skinageing related processes by means of several bioassays. All barks were successively extracted by $n$-heptane, methanol and methanol/water. The resulting samples were evaluated for their radical scavenging activity using the DPPH (1,1-diphenyl-2-picrylhydrazyl) assay, for their elastase, collagenase, and tyrosinase inhibitory activities using enzymatic assays, and for their antibacterial activity against Staphylococcus aureus, which is the most prevalent pathogen responsible for skin infections in occidental countries $[11,12]$. In parallel, the chemical profile of the 30 crude extracts was established by 1D and 2D NMR analyses in an attempt to discuss their global spectral patterns ( $\bullet$ Fig. 1) in relation to their biological activities.

\section{Results and Discussion}

In the present work, a collection of 10 barks from common deciduous and coniferous tree species was successively extracted with $n$-heptane, methanol, and methanol/water. As revealed by the extraction yields reported in $\odot$ Table 1 , the methanol extracts represented the most important quantities recovered from all tree species. The DPPH radical scavenging assay has been commonly used to evaluate the radical scavenging activity of plants and foods [13]. Although this assay involves only a single redox reaction and does not perfectly reflect the overall in vivo reactivity, it remains rapid and reproducible and can give an idea about the antioxidant activity of a sample. In the present work, we observed that the $n$-heptane bark extracts (E1-1 to E1-10) were

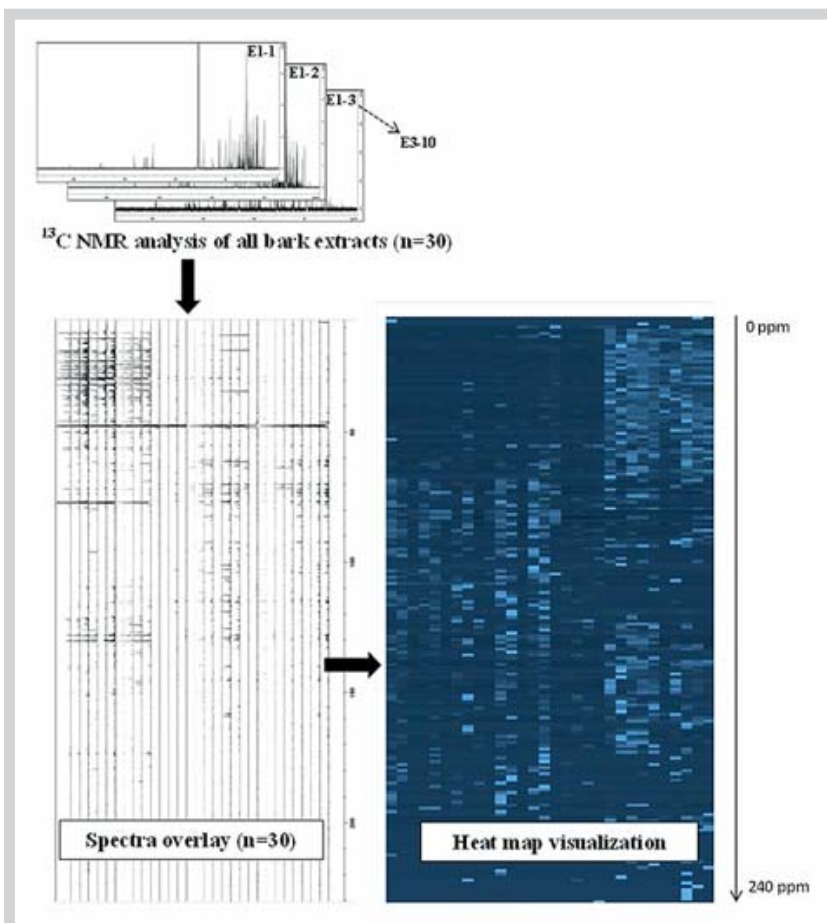

Fig. $1{ }^{13} \mathrm{C}$ NMR analysis of the crude bark extracts followed by automatic collection, binning, and visualization as a heat map of ${ }^{13} \mathrm{C}$ NMR signals. E1-1 to E1-10 correspond to $n$-heptane extracts. E2-1 to E2-10 correspond to the MeOH extracts. E3- 1 to E3-10 correspond to the $\mathrm{MeOH} / \mathrm{H}_{2} \mathrm{O}(50 / 50$, $\mathrm{v} / \mathrm{v}$ ) extracts. The higher the intensity of ${ }^{13} \mathrm{C}$ NMR peaks, the brighter the blue color on the map. (Color figure available online only.)

poorly active against the DPPH free radical. As indicated in - Fig. 2, a very slight scavenging effect was only observed for P. avium (E1-4), A. pseudoplatanus (E1-5), and F. excelsior (E16 ). By contrast, all of the methanol and methanol/water extracts exhibited DPPH radical scavenging effects, except A. pseudoplatanus (E2-5 and E3-5), for which the activity was below $10 \%$ even when tested at $200 \mu \mathrm{g} / \mathrm{mL}$. Particularly high scavenging activity was observed for the methanol extracts of Q. robur, A. glutinosa, L. decidua, and P. abies ( Fig. 2). These results are in accordance with previous studies reporting the antioxidant potential of different parts of Serbian oak species $Q$. robur and Q. petraea [14], or barks from $P$. abies [15]. The DPPH radical scavenging activity of $A$. glutinosa was also reported in the literature, but studies were focused on extracts obtained from the leaves [16] or on pure compounds isolated from the seeds [17].

\begin{tabular}{|c|c|c|c|c|}
\hline & \multirow[t]{3}{*}{ Tree species - voucher specimen } & E1 & E2 & E3 \\
\hline & & \multirow{2}{*}{ n-Heptane } & \multirow[t]{2}{*}{$\mathrm{MeOH}$} & $\mathrm{MeOH} / \mathrm{H}_{2} \mathrm{O}$ \\
\hline & & & & $50 / 50(v / v)$ \\
\hline 1 & F. sylvatica L. (Fagaceae) - JH-2014-1 & $0.3 \%$ & $2.4 \%$ & $1.8 \%$ \\
\hline 2 & Q. robur L. (Fagaceae) - JH-2014-2 & $0.4 \%$ & $5.6 \%$ & $3.0 \%$ \\
\hline 3 & A. glutinosa (L.) Gaertn. (Betulaceae) - JH-2014-3 & $1.1 \%$ & $5.6 \%$ & $1.7 \%$ \\
\hline 4 & P. avium L. (Rosaceae) - JH-2014-4 & $1.7 \%$ & $7.0 \%$ & $2.5 \%$ \\
\hline 5 & A. pseudoplatanus L. (Aceraceae) - JH-2014-5 & $1.1 \%$ & $1.4 \%$ & $1.5 \%$ \\
\hline 6 & F. excelsior L. (Oleaceae) - JH-2014-6 & $0.8 \%$ & $14 \%$ & $4.7 \%$ \\
\hline 7 & P. robusta C. K. Schneid. (Salicaceae) - JH-2014-7 & $0.6 \%$ & $8.3 \%$ & $3.1 \%$ \\
\hline 8 & L. decidua Mill. (Pinaceae) - JH-2014-8 & $0.9 \%$ & $6.7 \%$ & $3.8 \%$ \\
\hline 9 & P. abies (L.) H.Karst. (Pinaceae) - JH-2014-9 & $2.5 \%$ & $18.7 \%$ & $2.8 \%$ \\
\hline 10 & P. tremula L. (Salicaceae) - JH-2014-10 & $1.5 \%$ & $15.9 \%$ & $2.9 \%$ \\
\hline
\end{tabular}

Table 1 Extraction yields obtained after three successive extractions (E1, E2, and E3) of ten barks collected from deciduous and coniferous tress in the French Champagne-Ardenne region. 
In contrast, very little data is available regarding the antioxidant potential of $L$. decidua bark. Only one study investigated the content of the antioxidants glutathione, ascorbate, and tocopherol, and of the photoprotective pigments of European larch needles [18]. Here, the significant radical scavenging activities of methanol and methanol/water bark extracts were undoubtedly related to their high content in phenolic compounds, which exhibit wellknown antioxidant properties $[19,20]$. The ${ }^{13} \mathrm{C}$ NMR signals corresponding to these structural units can be easily observed in ${ }^{13} \mathrm{C}$ NMR spectral regions ranging from 100 to $160 \mathrm{ppm}$. As illustrated on the heat map of $\boldsymbol{Q}$ Fig. 1, the large majority of signals resulting from the ${ }^{13} \mathrm{C}$ NMR analyses of non-active $n$-heptane bark extracts (E1-1 to E1-10) were observed in the region of 20-60 ppm. These signals typically suggest the presence of alkyl groups belonging, for instance, to fatty acids or triterpenes [21]. These signal fingerprints are therefore unrelated to any DPPH radical scavenging activity. By contrast, the large majority of ${ }^{13} \mathrm{C}$ NMR signals corresponding to the methanol and methanol/water extracts (E2-1 to E2-10 and E3-1 to E3-10, respectively) were detected in the spectral region of $70-80 \mathrm{ppm}$ and $100-160 \mathrm{ppm}$, typically corresponding to glycosylated polyphenols [21] and directly linked to a significant radical scavenging activity ( $\mathbf{O}$ Fig. 2 ). Collagenases and elastases are matrix metalloproteinases (MMPs) constituting two families of key enzymes involved in the degradation of proteins contained in skin connective tissue. Collagenases are transmembrane zinc endopeptidases that break the peptide bonds of collagen, the most abundant constituent of the extracellular matrix. Elastases are serine proteases that break elastin fibers and determine, together with collagen, the mechanical properties of the skin including elasticity, strength, tissue remodeling, and wound healing capacity [22]. Under normal physiological conditions, the activity of elastases and collagenases are precisely regulated to ensure skin tissue homeostasis. Under oxidative stress or UV light exposure, these MMPs are overexpressed, resulting in skin disorders such as premature skin aging, inflammation, or, more seriously, degenerative diseases [23]. The search for natural substances able to inhibit elastase and collagenase activities is thus of great interest for the cosmetic and pharmaceutical industries.

- Fig. 3 represents the collagenase and elastase inhibitory activities of the 30 bark extracts. Considering elastase inhibition, it was observed that the activities were highly variable between the tested bark extracts. All $n$-heptane extracts displayed an elastase inhibitory activity below $50 \%$, indicating that nonpolar bark metabolites were poorly active. In contrast, methanol extracts, particularly those obtained from F. sylvatica, Q. robur, A. glutinosa, P. avium, L. decidua, and P. abies, exhibited the highest elastase inhibitory activities ( $\odot$ Fig. 3). Regarding the methanol/water extracts, F. sylvatica, Q. robur, P. avium, and L. decidua showed interesting elastase inhibitory activities.

Now considering the collagenase inhibition test, it was observed that the methanol bark extracts were globally more active than the $n$-heptane and methanol/water extracts, even if this tendency was less marked than for the other assays. As shown in - Fig. 3, some apolar $n$-heptane extracts that were absolutely not active against elastase displayed a slight but significant collagenase inhibitory activity, for instance, the $n$-heptane extract of $P$. avium. Among methanol extracts, the most potent were $Q$. robur, L. decidua, and P. abies ( $\odot$ Fig. 3). Interestingly, these three methanol extracts were already among the most efficient for DPPH radical scavenging and elastase inhibition. It was also noted that the methanol/water extracts of $Q$. robur and $L$. decidua displayed

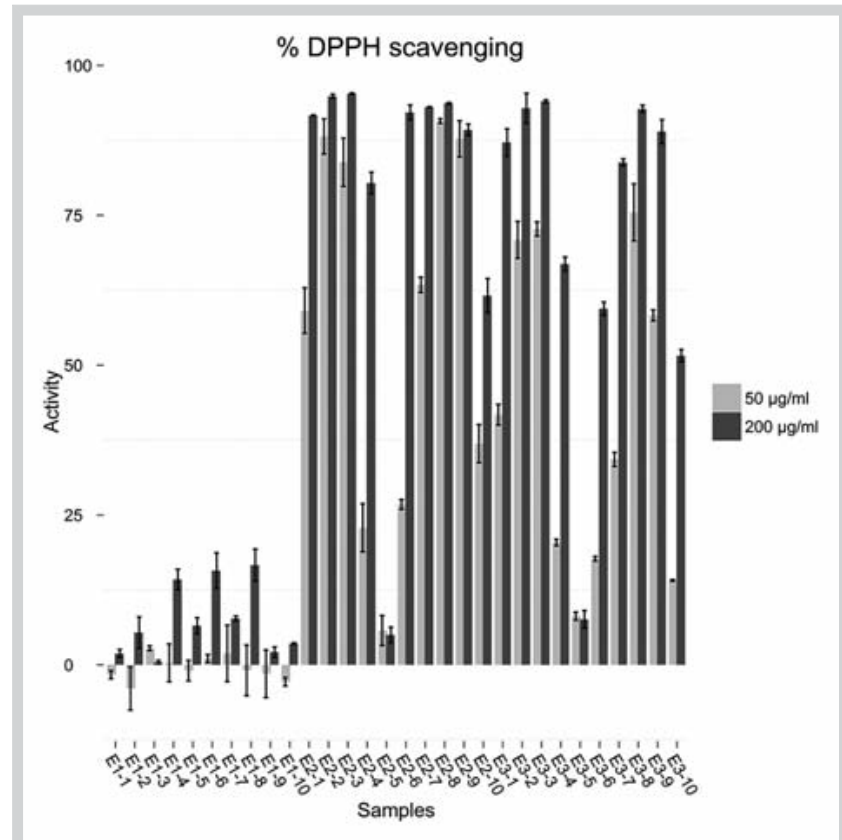

Fig. 2 DPPH radical scavenging activity and global chemical composition of 30 bark extracts obtained from deciduous and coniferous trees. E1-1 to E1-0: $n$-heptane extracts. E2-1 to E2-10: 100\% methanol extracts. E3-1 to E3-10: methanol/water 50/50 (v/v) extracts.

a strong effect against collagenase. Linking these results to the heat map containing the ${ }^{13} \mathrm{C}$ NMR signal patterns of the tested extracts ( $\odot$ Fig. 1 ), here again we can hypothesize that phenolic substances displaying signals in the spectral region of 100 160 ppm were involved in the elastase and collagenase inhibitory effects of the tested bark extracts. However, the variability of activities observed within methanol and methanol/water extracts indicate that further detailed analyses of their chemical profiles would be necessary to better understand structure-activity relationships. To our knowledge, this is the first time that elastase and collagenase inhibitory activities are reported for the European tree species examined in this work.

Tyrosinase is a key enzyme in the production of skin pigments in melanocytes. It catalyzes the hydroxylation of L-tyrosine to 3,4dihydroxyphenylalanine (L-DOPA) and the oxidation of L-DOPA to dopaquinone [24]. Both reactions constitute the first rate-limiting steps of the melanin biosynthesis pathway. The mushroom tyrosinase inhibition test is commonly used to study the whitening potential of natural extracts or pure molecules [25].

Here, the anti-tyrosinase effects of the 30 bark extracts are presented in 0 Fig. 4. The results were highly variable between tree species, and also between extracts for a single species. The methanol extract of $Q$. robur was the most active sample ( $\bullet$ Fig. 4). Tyrosinase inhibitory activities have already been reported for several species of the genus Quercus, for instance, Quercus infectoria G.Olivier [26] or Quercus dentata Thunb. [27], but never for the species $Q$. robur. Other methanol and methanol/water extracts such as F. sylvatica or L. decidua displayed significant tyrosinase inhibitory effects at $300 \mu \mathrm{g} / \mathrm{mL}$, but the inhibitory capacity was significantly decreased when these extracts were tested at $60 \mu \mathrm{g} / \mathrm{mL}$ (around 25\%). It can also be noted that concentration variabilities were observed for some extracts. For instance, $P$. avium and $P$. tremula showed an inhibitory activity higher than 

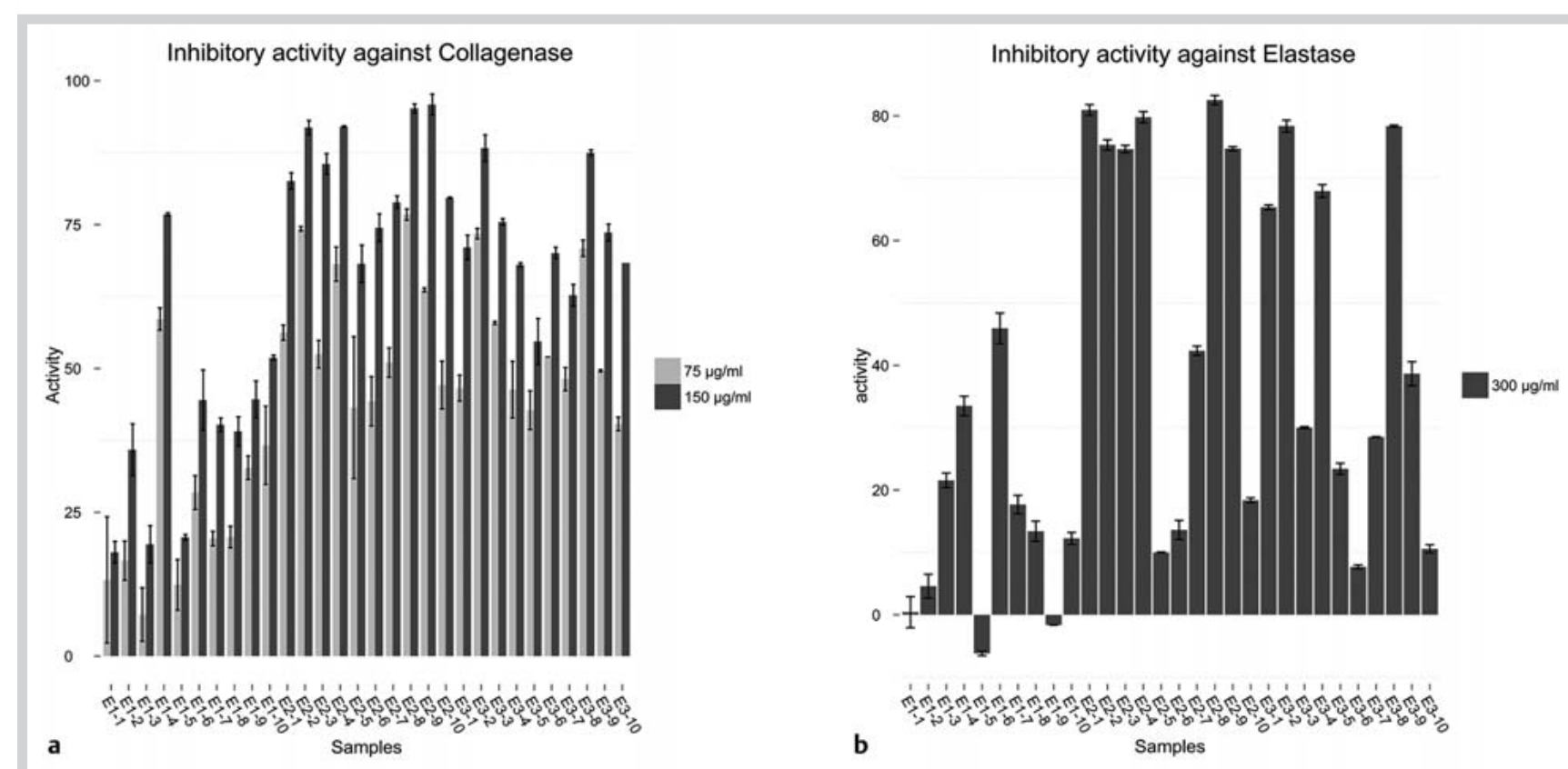

Fig. 3 Collagenase (a) and elastase (b) inhibitory activities, and global chemical composition of 30 bark extracts obtained from deciduous and

coniferous trees. E1-1 to E1-10: $n$-heptane extracts. E2-1 to E2-10: methanol extracts. E3-1 to E3-10: methanol/water 50/50 (v/v) extracts.
$40 \%$ when tested at $300 \mu \mathrm{g} / \mathrm{mL}$, whereas no activity was detected at 100 or $60 \mu \mathrm{g} / \mathrm{mL}$ ( $\odot$ Fig. 4). Even more unexpected, the inhibition percentage of some extracts were negative at specific concentrations. For instance, the tyrosinase inhibitory activities of the $n$-heptane extract of $L$. decidua were weakly positive when tested at 300 and $60 \mu \mathrm{g} / \mathrm{mL}$, but the inhibition value was reversed up to $-25.6 \pm 3.1 \%$ when tested at $100 \mu \mathrm{g} / \mathrm{mL}$. Negative inhibition values were also measured, for instance, after testing the methanol extract of $A$. glutinosa or the methanol/water extract of P. avium ( Fig. 4). These negative inhibition values were difficult to interpret because they were highly variable between samples and did not follow a clear tendency depending on the tested concentrations. We can only suggest that, at specific concentrations that would deserve to be investigated in more details, the extracts just mentioned above could possibly have the potential to enhance tyrosinase activity and, thus, enhance the production of L-DOPA.

The antibacterial activities of the 30 bark extracts were screened by bioautography against $S$. aureus. As illustrated in 0 Fig. 5 , the methanol bark extracts were generally more active than the other samples. Bacterial growth was not significantly inhibited in the presence of $n$-heptane extracts, while all methanol extracts displayed an antibacterial activity, with $Q$. robur and $L$. decidua being the most potent. Among the methanol/water extracts, only $Q$. robur, $L$. decidua, and $P$. abies showed an activity, but lower than that observed for the methanol extracts. These results indicate that the methanol extracts have a high efficiency against bacterial growing. Further work would be necessary to isolate and identify the active compounds of these promising crude extracts via bioactivity-guided fractionation. This task also needs to be pursued in order to characterize the active compound mechanisms involved in bacteriostatic or bacteriocidal actions.

In view of the results above, we initiated a chemical investigation of the four most active extracts by $1 \mathrm{D}\left({ }^{1} \mathrm{H}\right.$ and ${ }^{13} \mathrm{C}$ ) and $2 \mathrm{D}$ (HSQC, HMBC, COSY) NMR to identify the major chemical classes that

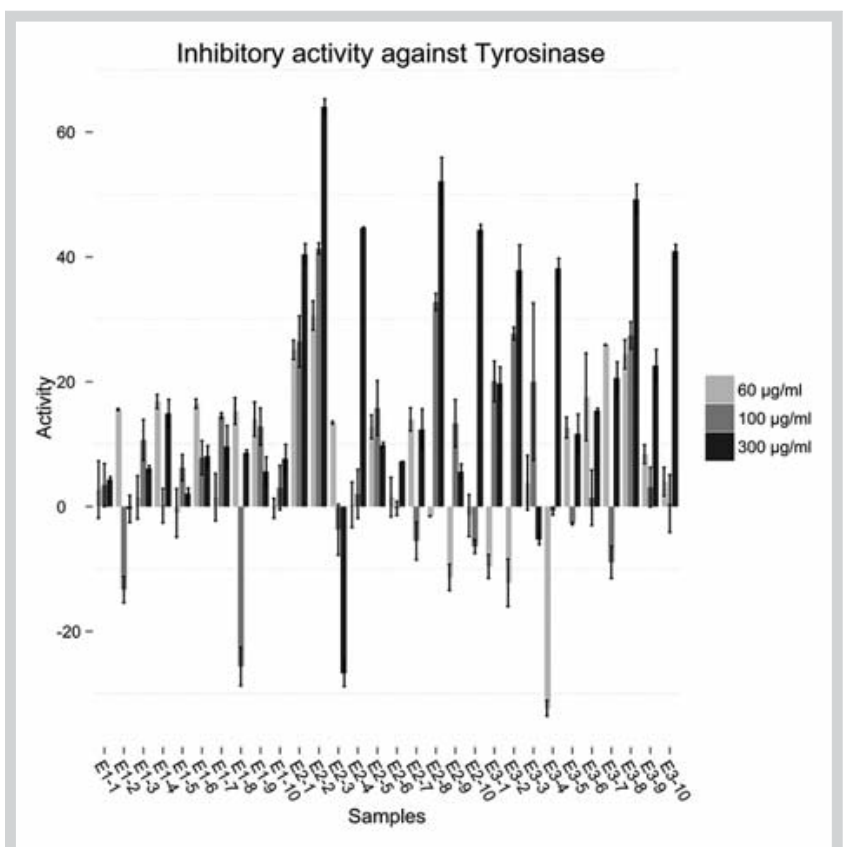

Fig. 4 Tyrosinase inhibitory activity of 30 bark extracts obtained from deciduous and coniferous trees. E1-1 to E1-10 correspond to $n$-heptane extracts. E2-1 to E2-10 correspond to 100\% methanol extracts. E3-1 to E3-10 correspond to methanol/water 50/50 (v/v) extracts.

could potentially be involved in the observed activities. The NMR spectra of $Q$. robur, A. glutinosa, $L$. decidua, and $P$. abies methanol extracts are given in $\odot$ Fig. 6. As already observed on the heat map representation of $\bullet$ Fig. 1 , the abundant signals detected in the spectral region between 100 and $160 \mathrm{ppm}$ indicated the presence of polyphenolic substances in the four extracts. 


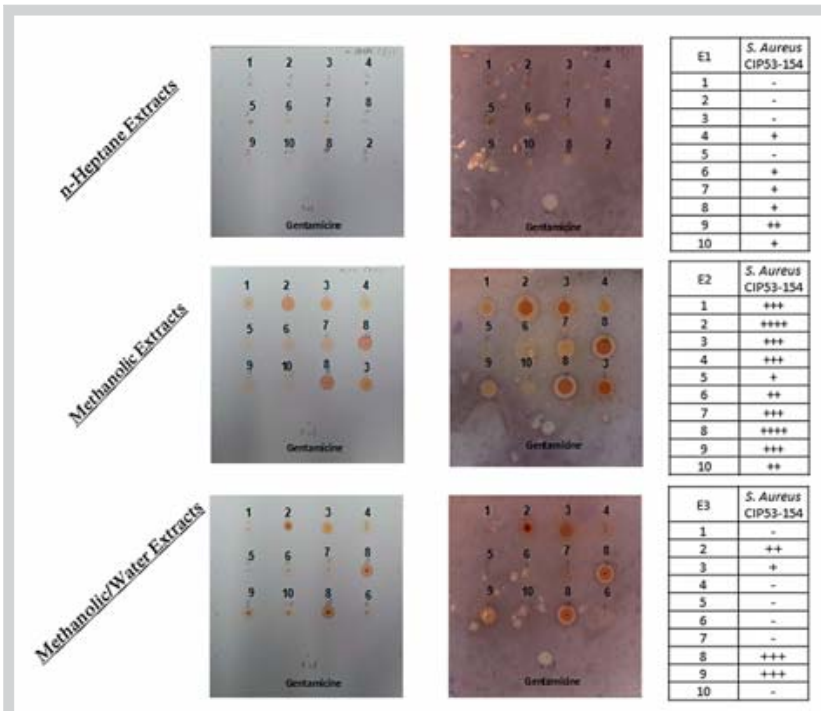

Fig. 5 In vitro antibacterial activity of all 30 bark extracts against S. aureus. (Color figure available online only.)

More precisely, the methanol extract of $Q$. robur contained a major compound identified by NMR as ellagic acid ( 0 Fig. $6 \mathbf{a}$ ) [28], several characteristic spectral patterns at $115 \mathrm{ppm}$ and $120 \mathrm{ppm}$, suggesting the presence of condensed tannins [29], as well as several minor signals in the sugar region $(70-90 \mathrm{ppm})$ and in the phenolic region (100-160 ppm) that could correspond to glycosylated polyphenols. These data are in accordance with previous studies reporting that besides lignocellulosic compounds, the bark of $Q$. robur also contains a diversity of polyphenols and, most especially, tannins and phenolic acids [30]. In the methanol extract of A. glutinosa, the major compound was identified by NMR as oregonin ( $\bullet$ Fig. $\mathbf{6 b}$ ) [31]. This diarylheptanoid was previously reported in the literature as a common metabolite of the genus Alnus, and was previously detected in the barks of A. glutinosa [32], Alnus hirsuta (Spach) Rupr. [33] and Alnus japonica (Thunb.) Steud. [34]. In the methanol extract of L. decidua, typical spectral patterns of condensed tannins at $115 \mathrm{ppm}$ and $145 \mathrm{ppm}$ were also detected by NMR ( $\mathbf{O}$ Fig. $\mathbf{~} \mathbf{c}$ ), suggesting the presence of proanthocyanidin units [35]. P. abies contained a largely major compound identified as astringin by 1D and 2D NMR analyses [36], as well as minor phenolic substances and condensed tannins ( $\boldsymbol{\otimes}$ Fig. $\mathbf{6 d}$ ). The structural complexity and diversity of condensed tannins make these compounds difficult to identify using only NMR. Purification and/or combination of several analytical techniques including, for instance, NMR to MALDI-TOF mass spectrometry, would be more suited to facilitate the identification of these compounds [37-39].

In summary, metabolites derived from the 10 barks of deciduous and coniferous tree species examined in this study showed promising applications in the production of active dermo-cosmetic ingredients. The methanol extracts of $Q$. robur, L. decidua, A. glutinosa, and $P$. abies showed significant radical scavenging capacities, elastase and collagenase inhibitory activities, as well as a growth inhibitory effect against gram-positive S. aureus bac-

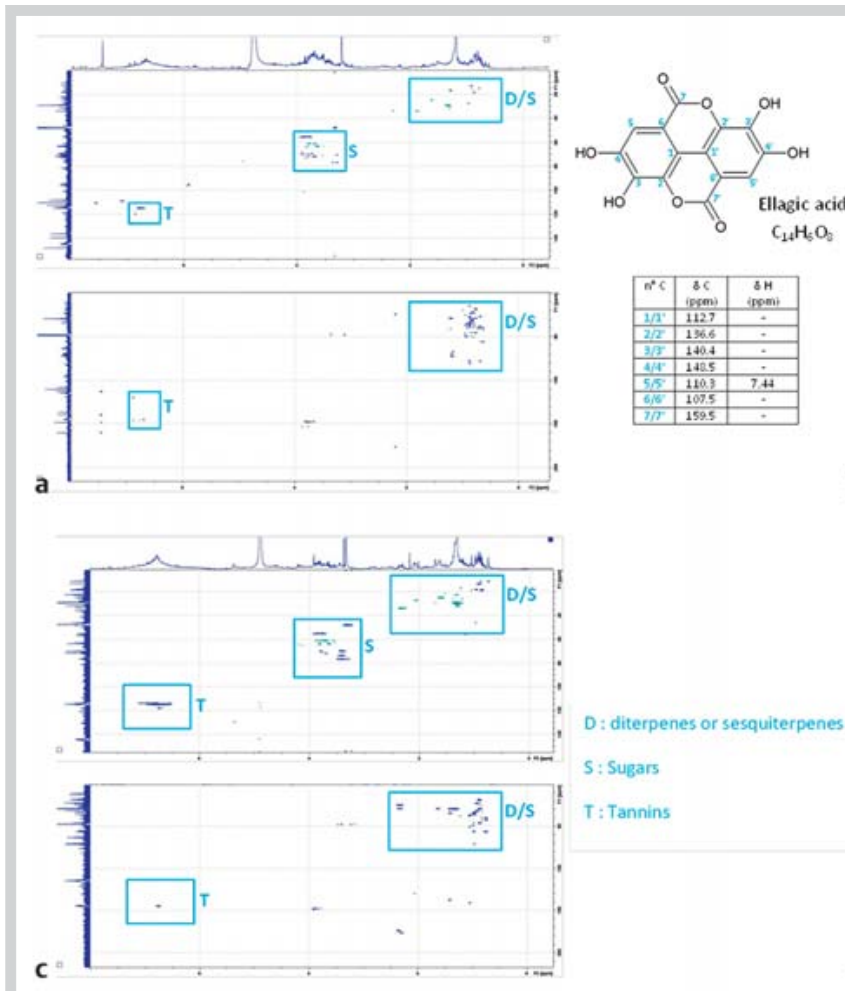

Fig. 6 2D NMR data (top: HSQC, bottom: HMBC). a Q. robur methanol extract (in methanol- $d_{4}$ ). The major compound was identified as ellagic acid. b A. glutinosa methanol extract (in methanol- $d_{4}$ ). The major compound was identified as oregonin. $\mathbf{c}$ L. decidua methanol extract (in methanol- $d_{4}$ ). $\mathbf{d} P$.
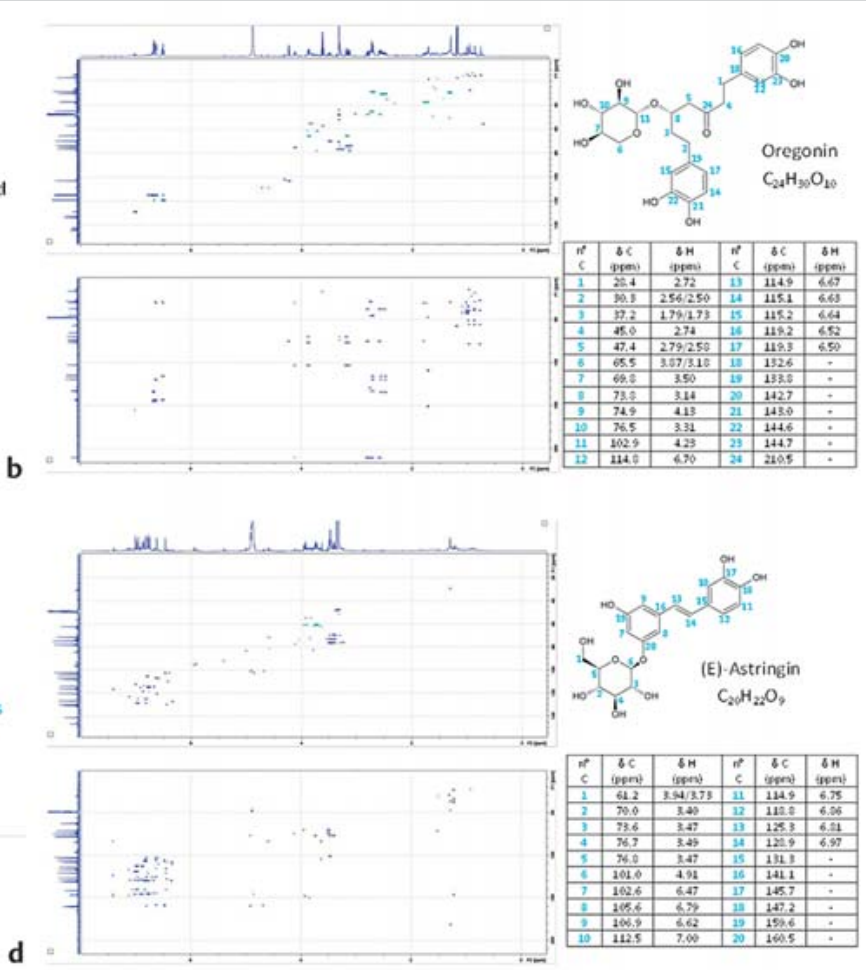

abies methanol extract (in methanol- $d_{4}$ ). The major compound was identified as (E)-astringin. D/S: diterpenes or sesquiterpenes; S: sugars; T: tannins. (Color figure available online only.) 
teria. These activities were undoubtedly related to the presence of phenolic substances in these extracts as revealed by their NMR spectral patterns. A more detailed chemical analysis and replicate multiple collection to cover a biological variability evaluation of these four potent bark extracts will be undertaken in the near future in order to determine precisely which compound(s) is responsible for the observed biological activities. A cytotoxicity evaluation will also be performed on skin explants before further considering a dermatological use of these extracts.

\section{Materials and Methods \\ $\nabla$}

Chemicals and reagents

$\mathrm{MeOH}$ and $n$-heptane were purchased from Carlo Erba Reactifs SDS. DPPH, ascorbic acid, deuterated methanol (methanol- $d_{4}$ ), deuterated chloroform (chloroforme- $d$ ), gentamicin, and MTT were purchased from Sigma-Aldrich. Deionized water $\left(\mathrm{H}_{2} \mathrm{O}\right)$ was used to prepare all aqueous solutions.

\section{Bark collection}

The barks of 10 trees ( Table 1 ) were collected in the forest of Signy l'Abbaye (barks 1-6) and in the national forest of Sedan (barks 7-10), both located in the Champagne-Ardenne region, northeast of France, in October 2014. For each species, about $2 \mathrm{~kg}$ of bark were manually removed from the trunk of a single tree at a height of $2 \mathrm{~m}$ two months after being axed down under professional forestry conditions. A voucher specimen of each bark sample has been deposited in the Herbarium of the Botanical laboratory at the faculty of Pharmacy of Reims, as given in $\bullet$ Table 1 (University of Reims Champagne-Ardenne, Reims, France).

\section{Preparation of the crude bark extracts}

All barks were dried at $30^{\circ} \mathrm{C}$ for $72 \mathrm{~h}$ and ground into a fine powder. A part of each powdered bark (200 g) was then extracted successively with $n$-heptane (E1), methanol (E2), and methanol/ water (50/50, v/v) (E3). Extractions were performed under magnetic stirring for $24 \mathrm{~h}$ at room temperature using $3 \mathrm{~L}$ of solvent each time. After filtration and solvent elimination under vacuum, the dry residues were weighted. The extraction yields are reported in $\odot$ Table 1.

\section{DPPH radical scavenging activity}

The DPPH radical scavenging assay was performed according to a previously described method [40], with slight modifications. The stock DPPH solution $(314 \mu \mathrm{M})$ was prepared by diluting $12.4 \mathrm{mg}$ in $100 \mathrm{~mL}$ absolute ethanol. Then, it was vortexed and kept in the dark at room temperature until its use. Gallic acid (purity > 98\%; Sigma-Aldrich) was used as a positive control at a concentration of $29.4 \mu \mathrm{M}$. The crude bark extracts were diluted in DMSO at final concentrations of 50 and $200 \mu \mathrm{g} / \mathrm{mL}$. In a microwell plate, $190 \mu \mathrm{L}$ of the DPPH solution and $10 \mu \mathrm{L}$ of gallic acid or samples were added. When DPPH reacts with an antioxidant compound, which can donate hydrogen, it is reduced. The changes in color (from deep violet to light yellow) were read [absorbance (Abs)] at $517 \mathrm{~nm}$ after $30 \mathrm{~min}$ of incubation in the dark at room temperature using the reader Infinite 200 PRO series (Tecan). Experiments were performed in triplicate for each sample. A negative control containing $10 \mu \mathrm{L}$ DMSO and $190 \mu \mathrm{L}$ DPPH was performed each time. Blanks contained $190 \mu \mathrm{L}$ EtOH and $10 \mu \mathrm{L}$ sample. All materials were purchased from Sigma-Aldrich. The radical scav- enging activity percentage (AA\%) was determined as follows:

$A A \%=\left\{100-\left[\left(A_{\text {sample }}-A_{\text {blank }}\right) / A_{\text {control }}\right]\right\} \times 100$

where $A_{\text {control }}$ is the absorbance of the negative control, $A_{\text {sample }}$ is the absorbance after the reaction of samples with DPPH, and $A_{\text {blank }}$ is the absorbance of samples with EtOH instead of DPPH.

\section{Elastase inhibitory activity}

The porcine pancreatic elastase type IV (PPE), a lyophilized powder at $\geq 4$ units/mg protein (EC Number 254-453-6, Sigma-Aldrich), was used for this bioassay. PPE inhibition was tested spectrophotometrically according to a previously described method, with slight modifications [41], using N-succinyl-Ala-Ala-Ala-pnitroanilide (Sigma-Aldrich, EC Number 257-823-5) as the substrate and monitoring the release of $p$-nitroaniline. The amount of $p$-nitroaniline was determined by measuring the absorbance at $405 \mathrm{~nm}$. The reaction mixture initially contained $70 \mu \mathrm{L}$ Trizma-base buffer ( $50 \mathrm{mM}, \mathrm{pH}=7.5$ ), $10 \mu \mathrm{L}$ of bark extract ( $3 \mathrm{mg}$ / $\mathrm{mL}$ in buffer) and $5 \mu \mathrm{L}$ of elastase $(0.4725 \mathrm{U} / \mathrm{mL})$. The resulting solutions were incubated for $15 \mathrm{~min}$ at room temperature, avoiding light exposure. Afterwards, $15 \mu \mathrm{L}$ of $2 \mathrm{mM}$ N-succinyl-Ala-AlaAla- $p$-nitroanilide dissolved in Trizma buffer were added and the mixtures were incubated for $30 \mathrm{~min}$ at $37^{\circ} \mathrm{C}$. Elastatinal (Sigma-Aldrich), which is a strong irreversible competitive inhibitor of PPE, was used as a positive control ( $\mathrm{IC}_{50}=0.5 \mu \mathrm{g} / \mathrm{mL}$ ). Experiments were performed in triplicate. Absorbances were measured using the reader Infinite 200 PRO series (Tecan). Trizma-base and DMSO were purchased from Sigma-Aldrich. The inhibition percentage of elastase was calculated by the formula in section 2.4, where $A_{\text {control }}$ is the absorbance of the mixture containing the buffer, elastase, the sample solvent, and the substrate, and $A_{\text {sample }}$ is the absorbance of the buffer, elastase, extract or elastatinal, and substrate mixture. Blank experiments were performed for each sample with all the reagents except the enzyme.

\section{Collagenase inhibitory activity}

Collagenase from Clostridium histolyticum, released from physiologically active rat pancreatic islets Type $\mathrm{V}, \geq 1$ FALGPA units/mg solid, > 125 CDU/mg solid (EC number: 232-582-9), was purchased from Sigma-Aldrich. The spectrofluorimetric method of Ohtsuki T. et al. [42] modified by Moon et al. [43] was used to determine the anti-collagenase activity of the crude bark extracts. In a 96 -well microwell plate, $25 \mu \mathrm{L}$ of Tris- $\mathrm{HCl}$ buffer $(10 \mathrm{mM}$, $\mathrm{pH}=7.3), 25 \mu \mathrm{L}$ of sample [dissolved in Tris- $\mathrm{HCl}$ buffer $(<2 \%$ DMSO) from 600 to $300 \mu \mathrm{g} / \mathrm{mL}$ ], and $25 \mu \mathrm{L}$ of collagenase from C. histolyticum $(100 \mu \mathrm{g} / \mathrm{mL}$ in Tris- $\mathrm{HCl}$ buffer) were preincubated for $10 \mathrm{~min}$ at $37^{\circ} \mathrm{C}$. Afterwards, $25 \mu \mathrm{L}$ of MMP2 substrate (MCAPro-Leu-Ala-Nva-DNP-Dap-Ala-Arg-NH2; Sigma-Aldrich) solution in buffer at an initial concentration of $50.8 \mu \mathrm{M}$ were added. The fluorescence values (fluorescent intensity) were measured at an excitation maximum of $320 \mathrm{~nm}$ and an emission maximum of $405 \mathrm{~nm}$ after $30 \mathrm{~min}$ incubation at $37^{\circ} \mathrm{C}$ using a fluorescence plate reader (Galaxy fluo star). Light exposure was avoided during the incubation periods. Phosphramidon (Sigma-Aldrich), a metallo-endopeptidase inhibitor, was used as a positive control $\left(\mathrm{IC}_{50}=6.9 \mu \mathrm{M}\right)$. All assays were performed in triplicate. Tris- $\mathrm{HCl}$ and DMSO were purchased from Sigma-Aldrich. The inhibition percentage was calculated as follows: 
Inhibition $(\%)=\left\{\left[\left(\mathrm{F}_{\text {control }}-\mathrm{F}_{\text {control's blank }}\right)-\left(\mathrm{F}_{\text {sample }}-\mathrm{F}_{\text {sample's }}\right.\right.\right.$ blank $\left.)] /\left(\mathrm{F}_{\text {control }}-\mathrm{F}_{\text {control's blank }}\right)\right\} \times 100$

where $\mathrm{F}_{\text {control }}$ is the fluorescence of buffer, collagenase, sample solvent, and substrate and $\mathrm{F}_{\text {sample }}$ is the absorbance of buffer, collagenase, extract or phosphoramidon, and substrate. Blanks contained all the components except the enzyme.

\section{Tyrosinase inhibitory activity}

Mushroom tyrosinase, a lyophilized powder, $\geq 1000$ units/mg solid (EC Number: 1.14.18.1), was purchased from Sigma-Aldrich. The capacity of the crude bark extracts to inhibit the catalytic action of tyrosinase in the oxidation of L-DOPA to dopachrome was determined by an enzymatic method described by Masuda et al. [44], with some modifications. Tyrosinase activity was measured at $475 \mathrm{~nm}$ using the reader Infinite 200 PRO series (Tecan). The inhibitory potency of the bark extracts against this enzyme was compared with those of two positive controls, kojic acid ( $\mathrm{IC}_{50}=14 \mu \mathrm{M}$, purity 99\%, Sigma-Aldrich), known as strong antihyperpigmentation agent, and a methanolic extract from the root of Glycyrrhiza glabra L. (Fabaceae; $5 \mu \mathrm{g} / \mathrm{ml}$ ), which has been proven to be a potent whitening agent [45]. In a 96-well microplate, $80 \mu \mathrm{L}$ of PBS $(1 / 15 \mathrm{M}, \mathrm{pH}=6.8), 40 \mu \mathrm{L}$ of the tested extract (dissolved in the PBS buffer from 1.5 to $0.3 \mathrm{mg} / \mathrm{mL}$ ), and $40 \mu \mathrm{L}$ of mushroom tyrosinase $92 \mathrm{U} / \mathrm{ml}$ were mixed and incubated for $10 \mathrm{~min}$ at room temperature, avoiding light exposure. Afterwards, $40 \mu \mathrm{L}$ of $2.5 \mathrm{mM}$ L-DOPA (purity $>98 \%$, Sigma-Aldrich) dissolved in buffer were added and the mixture was incubated for $5 \mathrm{~min}$ before measurement of dopachrome formation at $475 \mathrm{~nm}$. Experiments were performed in triplicate. The final DMSO concentrations did not exceed $3 \%$ of the total volume and did not affect the final results. Mono- and di-basic sodium phosphate and DMSO were purchased from Sigma-Aldrich. The inhibition percentage was calculated as follows:

Inhibition $(\%)=\left\{\left[\left(A_{\text {control }}-A_{\text {control's blank }}\right)-\left(A_{\text {sample }}-A_{\text {sample's }}\right.\right.\right.$ blank $\left.)] /\left(\mathrm{A}_{\text {control }}-\mathrm{A}_{\text {control's blank }}\right)\right\} \times 100$

where $\mathrm{A}_{\text {control }}$ is the absorbance of the mixture consisting of buffer, tyrosinase, sample solvent, and substrate and $A_{\text {sample }}$ is the absorbance of the mixture of buffer, tyrosinase, bark extract or kojic acid/G. glabra solutions, and substrate. Blanks contained all the abovementioned components except the enzyme.

\section{In vitro antibacterial activity against \\ Staphylococcus aureus}

The Mueller-Hinton Agar and broth media were purchased from Biokar. S. aureus CIP 53.154 strain was provided by the Institut Pasteur. The antibacterial activity of the 30 bark extracts was determined by an immersion bioautography method [46]. An aliquot of each extract $(20 \mathrm{mg}$ ) was solubilized in $1 \mathrm{~mL}$ of chloroforme ( $n$-heptane extracts from E1-1 to E1-10) or $1 \mathrm{~mL}$ of methanol (methanol extracts from E2-1 to E2-10 and methanol/water extracts from E3-1 to E3-10). The resulting solutions were spotted onto three independent Merck 60 F254 precoated silica gel plates $(10 \times 10 \mathrm{~cm})$. One plate was prepared for the $n$-heptane extracts, one for the methanol extracts, and one for the methanol/ water extracts. Gentamicin $(50 \mu \mathrm{g})$ was also spotted on the three plates as a positive control. The TLC plates were directly dried without migration and sterilized. The plates were then covered by Mueller-Hinton ( $\mathrm{MH}$ ) agar medium containing an S. aureus CIP 53.154 suspension $\left(10^{5}\right.$ bacteria/mL) in square petri dishes.
After incubation at $37^{\circ} \mathrm{C}$ for $24 \mathrm{~h}$, bacterial growth was revealed by a $2-\mathrm{mg} / \mathrm{mL}$ solution of MTT and growth inhibition zones were measured manually. White stains indicated where a reduction of MTT to the colored formazan did not take place due to the presence of extracts that inhibited bacterial growth. Solvents were also checked for absence of antibacterial activity.

\section{NMR analyses and heat map visualization}

An aliquot of each bark extract $(\approx 20 \mathrm{mg}$ ) was dissolved in $600 \mu \mathrm{L}$ of chloroform- $d$ ( $n$-heptane extracts) or methanol- $d_{4}$ (methanol and methanol/water extracts) and analyzed by ${ }^{13} \mathrm{C}$ NMR at $298 \mathrm{~K}$ on a Bruker Avance AVIII-600 spectrometer equipped with a TXI cryoprobe. ${ }^{13} \mathrm{C}$ NMR spectra were acquired at $150.91 \mathrm{MHz}$. A standard zgpg pulse sequence was used with an acquisition time of $0.9 \mathrm{~s}$ and a relaxation delay of $3 \mathrm{~s}$. For each sample, a total of 1024 scans were co-added to obtain a satisfactory signal-tonoise ratio. The spectral width was $240 \mathrm{ppm}$ and the receiver gain was set to the highest possible value. Spectra were then manually phased and baseline corrected using TOPSPIN 3.2 software (Bruker) and calibrated on the central resonance of methanol- $d_{4}(\delta 49.10 \mathrm{ppm})$. The next step consisted in the binning of all ${ }^{13} \mathrm{C}$ NMR spectra followed by the visualization of the whole set of signals as a heat map. For this purpose, the absolute intensities of all ${ }^{13} \mathrm{C}$ NMR signals detected in the 30 spectra were automatically collected and each resulting peak list was stored as a text file. The binning step was performed by a locally developed computer script written in Python language. Its principle was to divide the ${ }^{13} \mathrm{C}$ spectral width (from 0 to $240 \mathrm{ppm}$ ) into regular chemical shift windows $(\Delta \delta=1 \mathrm{ppm})$, and to associate the absolute intensity of each ${ }^{13} \mathrm{C}$ peak (and that for all peak lists) to the corresponding bin. The resulting table was imported into PermutMatrix version 1.9.3 software (LIRMM, Montpellier, France) for data visualization as a two-dimensional heat map. Each column of the heat map corresponds to a sample $(n=30)$ and each row corresponds to a chemical shift window. The absolute peak intensities were normalized between samples. The higher the intensity of ${ }^{13} \mathrm{C}$ NMR peaks, the brighter the color on the map. The binning workflow and resulting heat map are illustrated in o Fig. 1. Additional 2D NMR analyses (HSQC, HMBC, and COSY) were performed on the most active extracts using standard Bruker pulse sequences.

\section{Acknowledgements}

\section{$\nabla$}

The authors thank the CNRS and the Ministry of Higher Education and Research for financial support as well as the EU program FEDER for the PIAneT CPER project. The forestry harvesting company Hubert Cie (Illy, France) is also gratefully acknowledged for identification, collection, and provision of barks from various tree species.

\section{Conflict of Interest \\ $\nabla$}

The authors declare no conflict of interest.

\footnotetext{
Affiliations

${ }^{1}$ Institut de Chimie Moléculaire de Reims, UMR CNRS 7312, SFR CAP'SANTE, UFR de Pharmacie, Université de Reims Champagne-Ardenne, Reims, France

2 Division of Pharmacognosy and Natural Products Chemistry, School of Pharmacy, University of Athens, Panepistimioupolis, Zographou, Athens, Greece
} 
${ }^{3}$ Biomatériaux et Inflammation en Site Osseux, EA 4691, SFR CAP-Santé, UFR de Pharmacie, Université de Reims Champagne Ardenne, Reims, France

${ }^{4}$ Soliance-Givaudan, Pomacle, France

\section{References}

1 Adams EE. World forest area still on the decline. Available at http:// www.earth-policy.org/indicators/C56/forests_2012. Accessed 01/2012

2 FAO. State of the world's forests 2011. Available at http://www.fao.org/ docrep/013/i2000e/i2000e.pdf Accessed 01/2011

3 Yang XW, Li SM, Shen YH, Zhang WD. Phytochemical and biological studies of Abies species. Chem Biodivers 2008; 5: 56-81

4 Kostova I, Iossifova T. Chemical components of Fraxinus species. Fitoterapia 2007; 78: 85-106

5 Nahrstedt A, Schmidt M, Jäggi R, Metz J, Khayyal MT. Willow bark extract: the contribution of polyphenols to the overall effect. Wien Med Wochenschr 2007; 157: 348-351

6 de Oliveira ARM, Szczerbowski D. Quinine: 470 years of history, controversy and science development. Quim Nova 2009; 32: 1971-1974

7 Zofou D, Ntie-Kang F, Sippl W, Efange SM. Bioactive natural products derived from the Central African flora against neglected tropical diseases and HIV. Nat Prod Rep 2013; 30: 1098-1120

8 Crag GM. Paclitaxel (Taxol): a success story with valuable lessons for natural product drug discovery and development. Med Res Rev 1998; 18: 315-331

9 Król SK, Kiełbus M, Rivero-Müller A, Stepulak A. Comprehensive review on betulin as a potent anticancer agent. Biomed Res Int 2015; 2015: 584189

10 Frédérich M, Marcowycz A, Cieckiewicz E, Mégalizzi V, Angenot L, Kiss R. In vitro anticancer potential of tree extracts from the Walloon region forest. Planta Med 2009; 75: 1634-1637

11 Amin AN, Cerceo EA, Deitelzweig SB, Pile JC, Rosenberg DJ, Sherman BM. Hospitalist perspective on the treatment of skin and soft tissue infections. Mayo Clin Proc 2014; 89: 1436-1451

12 Larru B, Gerber JS. Cutaneous bacterial infections caused by Staphylococcus aureus and Streptococcus pyogenes in infants and children. Ped Clin North Am 2014; 61: 457-478

13 Tan JBL, Lim YY. Critical analysis of current methods for assessing the in vitro antioxidant and antibacterial activity of plant extracts. Food Chem 2015; 172: 814-822

14 Popović BM, Stajner D, Zdero R, Orlović S, Galić Z. Antioxidant characterization of oak extracts combining spectrophotometric assays and chemometrics. ScientificWorldJournal 2013; 2013: 134656

15 Co M, Fagerlund A, Engman L, Sunnerheim K, Sjöberg PJR, Turner C. Extraction of antioxidants from Spruce (Picea abies) bark using ecofriendly solvents. Phytochem Anal 2012; 23: 1-11

16 Mushkina OV, Gurina NS, Konopleva MM, Bylka W, Matlawska I. Activity and total phenolic content of Alnus glutinosa and Alnus incana leaves. Acta Sci Polon 2013; 12: 3-11

17 Kumarasamy Y, Cox PJ, Jaspars M, Nahar L, Sarker SD. Bioactivity of hirsutanolol, oregonin and genkwanin, isolated from the seeds of Alnus glutinosa (Betulaceae). Nat Prod Com 2006; 1: 641-644

18 Hecke K, Tausz M, Gigele T, Havranek WM, Anfodillo T, Grill D. Foliar antioxidants and protective pigments in Larix decidua Mill. from contrasting elevations in the Northern and Southern Tyrolean Limestone Alps. Forstwiss Centralbl 2003; 122: 368-375

19 Stevenson $D E$, Hurst RD. Polyphenolic phytochemicals - just antioxidants or much more? Cell Mol Life Sci 2007; 64: 2900-2916

20 Alov P, Tsakovska I, Pajeva I. Computational studies of free radical-scavenging properties of phenolic compounds. Curr Top Med Chem 2015; 15: 85-104

21 Pretsch E, Bühlmann P, Badertscher M. Structure determination of organic compounds: tables of spectral data. Fourth, revised and enlarged edition. Berlin: Springer-Verlag; 2009: 1-443

22 Imokawa G, Ishida $K$. Biological mechanisms underlying the ultraviolet radiation-induced formation of skin wrinkling and sagging I: reduced skin elasticity, highly associated with enhanced dermal elastase activity, triggers wrinkling and sagging. Int J Mol Sci 2015; 16: 7753-7775

23 Rittie L, Fisher GJ. UV-light-induced signal cascades and skin aging. Ageing Res Rev 2002; 1: 705-720

24 Casanola-Martin GM, Le-Thi-Thu H, Marrero-Ponce Y, Castillo-Garit JA, Torrens F, Rescigno A, Abad C, Khan MT. Tyrosinase enzyme: 1. An overview on a pharmacological target. Cur Top Med Chem 2014; 14: 14941501
$25 \mathrm{Wu}$ B. Tyrosinase inhibitors from terrestrial and marine resources. Curr Top Med Chem 2014; 14: 1425-1449

26 Khazaeli P, Goldoozian R, Sharififar F. An evaluation of extracts of five traditional medicinal plants from Iran on the inhibition of mushroom tyrosinase activity and scavenging of free radicals. Int J Cosm Sci 2009; 31: $375-381$

27 Hwang JH, Lee BM. Inhibitory effects of plant extracts on tyrosinase, LDOPA oxidation, and melanin synthesis. J Toxicol Env Health 2007; 70: 393-407

28 Nawwar MAM, Hussein SAM, Merfort I. NMR spectral analysis of polyphenols from Punica granatum. Phytochem 1994; 36: 793-798

29 Zhang LL, Lin YM, Zhou HC, Wei SD, Chen JH. Condensed tannins from mangrove species Kandelia candel and Rhizophora mangle and their antioxidant activity. Molecules 2010; 15: 420-431

30 Dedrie M, Jacquet N, Bombeck PL, Bombeck PL, Hebert J, Richel A. Oak barks as raw materials for the extraction of polyphenols for the chemical and pharmaceutical sectors: A regional case study. J Ind Crops Prod 2015; 70: 316-321

31 Kuroyanagi M, Shimomae M, Nagashima Y, Muto N, Okuda T, Kawahara $N$, Nakane T, Sano T. New diarylheptanoids from Alnus japonica and their antioxidative activity. Chem Pharm Bull 2005; 53: 1519-1523

32 Novaković M, Pešić M, Trifunović S, Vučković I, Todorović N, PodolskiRenić A, Dinić J, Stojković S, Tešević V, Vajs V, Milosavljević S. Diarylheptanoids from the bark of black alder inhibit the growth of sensitive and multi-drug resistant non-small cell lung carcinoma cells. Phytochem 2014; 97: 46-54

33 Park D, Kim HJ, Jung SY, Yook CS, Jin C, Lee YS. A new diarylheptanoid glycoside from the stem bark of Alnus hirsuta and protective effects of diarylheptanoid derivatives in human HepG2 cells. Chem Pharm Bull 2010; 58: 238-241

34 Nguyen Huu T, Sun K, Fan JY, Shoyama Y, Han JY. Oregonin from the bark of Alnus japonica restrained ischemia-reperfusion-induced mesentery oxidative stress by inhibiting NADPH oxidase activation. Microcirculation 2014; 21: 688-695

35 Vázquez G, Pizzi A, Sonia Freire M, Santos J, Antorrena G, González-Álvarez J. MALDI-TOF, HPLC-ESI-TOF and $13 \mathrm{C}$-NMR characterization of chestnut (Castanea sativa) shell tannins for wood adhesives. Wood Sci Technol 2013; 47: 523-535

36 Li SH, Schneider B, Gershenzon J. Microchemical analysis of laser-microdissected stone cells of Norway spruce by cryogenic nuclear magnetic resonance spectroscopy. Planta 2007; 225: 771-779

37 Shoji T, Mutsuga M, Nakamura T, Kanda T, Akiyama H, Goda Y. Isolation and structural elucidation of some procyanidins from apple by lowtemperature nuclear magnetic resonance. J Agric Food Chem 2003; 51: 3806-3813

38 Navarrete P, Pizzi A, Pasch H, Rode K, Delmotte L. MALDI-TOF and C-13 NMR characterization of maritime pine industrial tannin extract. J Ind Crops Prod 2010; 2: 105-110

39 Esatbeyoglu T, Jaschok-Kentner B, Wray V, Winterhalter P. Structure elucidation of procyanidin oligomers by low-temperature H-1 NMR spectroscopy. J Agric Food Chem 2011; 59: 62-69

40 Lee SK, Mbwambo ZH, Chung HS, Luyengi L, Gamez EJC, Mehta RG, Kinghorn $A D$, Pezzuto JM. Evaluation of the antioxidant potential of natural products. Combin Chem High Throughput Screen 1998; 1: 35-46

41 Kwan JC, Taori K, Paul VJ, Luesch H. Lyngbyastatins 8-10, elastase inhibitors with cyclic depsipeptide scaffolds isolated from the marine cyanobacterium Lyngbya semiplena. Mar Drug 2009; 7: 528-538

42 Ohtsuki T, Yokosawa E, Koyano T, Preepram S, Kowithayakorn T, Sakai S, Toida T, Ishibashi M. Quinic acid esters from Pluchea indica with collagenase, MMP-2 and MMP-9 inhibitory activities. Phytotherap Res 2008; 22: 264-266

43 Moon HI, Kim TI, Cho HS, Kim EK. Identification of potential and selective collagenase, gelatinase inhibitors from Crataegus pinnatifida. Bioorg Med Chem Lett 2010; 20: 991-993

44 Masuda T, Yamashita D, Takeda Y, Yonemori S. Screening for tyrosinase inhibitors among extracts of seashore plants and identification of potent inhibitors from Garcinia subelliptica. Biosci Biotechnol Biochem 2005; 69: 197-201

45 Dong Y, Zhao M, Zhao T, Feng M, Chen H, Zhuang M, Lin L. bioactive profiles, antioxidant activities, nitrite scavenging capacities and protective effects on $\mathrm{H}_{2} \mathrm{O}_{2}$-injured PC12 cells of Glycyrrhiza glabra L. leaf and root extracts. Molecules 2014; 19: 9101-9113

46 Rahalison L, Hamburger M, Hostettmann $K$, Monod M, Frenk E. A bioautographic agar overlay method for the detection of antifungal compounds from higher plants. Phytochem Anal 1991; 2: 199-203 